\title{
South Korean Cort/Cor-tek Guitar Workers' Action and the Politics of Digital International Solidarity
}

\section{Introduction}

I play a Cort guitar. I inherited it from my mother when she gave up on learning campfire songs. When she gave it to me, she said she had been told that Corts were known for having impressive sound quality for a surprisingly low price, but it was only about a decade later that it occurred to me to wonder why. The reason, I learned, has to do with an ongoing history of corporate violence and workers organizing against the South Korean Cort/Cor-tek Guitars and Basses company. The company, in turn, has sought yet cheaper and more docile labour in China and Indonesia, keeping prices low and profits high even as Korean Cort/Cor-tek workers (hereafter "Cort workers") have mounted an international solidarity campaign. Under the page heading “Workers' Stories” of the webpage Cort Guitar Workers ACTION!: Guitar Workers + Musicians United! a litany of harrowing stories are framed by these lines:

For 10, 20, 30 years,

Working in solvent and fumes in factories without windows...

Forced to work overtime, and never able to see your family...

Injuries, harassment, verbal abuse... and the final indignity- a mass firing under the cover of a sham bankruptcy.

This paper explores the trajectory of Cort Guitar Workers Action (CGWA) campaign against these injustices, showing how it has used the aesthetic force of popular music as an international language to forge solidary links with Western music industries, often using the enabling constraints of digitally mediated international solidarity.

In what follows, I synthesize a picture of CGWA from the nodes of what might be called the "weak network" of digital solidarity formed by the Cort/Cor-tek workers. As we will see, it is a limited, yet meaningful, kind of solidarity that emerges through such a group "constituted by extensive, yet casual and limited social interaction" (Stalder 2013: 31). Weak digital networks are those where "lots of difference" can be accommodated since "the areas of shared understanding and knowledge are, by definition, limited" (Stalder 2013: 44), and that is certainly the case for CGWA. The movement materialized online through Korean- and English-language 
Wordpress blogs, Facebook pages, an English-language Twitter account, and a series of English-captioned YouTube videos, none of which support extensive ongoing online interaction. The hub of CGWA that is the cadre of dismissed Cort workers embodies (apparently acephalously) the discipline and strategy needed to sustain the project over time, while the social media presence creates "weak ties" (Granovetter 1973) to bridge outside itself. (These ties are also made in person at the many appearances CGWA makes at music festivals, trade shows, and other events, but aside from manifesting the negative action of boycotting Cort, the activity of weak ties is channeled by CGWA back into the positive activity of posting and sharing campaign materials online. This is consistent with the findings of some studies that online and offline activisms are not independent constructs, but rather captured by a model of “hybrid activism” [eg. Milošević-Dordević \& Žeželj 2017]). Such weak ties, as Mark Granovetter (1973) famously argued in "The Strength of Weak Ties," are highly valuable for activism because "people rarely act on mass-media information unless it is also transmitted through personal ties" (1374). The greater the number of paths between a leader and followers, encourages trust, while "organizations dominated by strong ties tend to produce fragmentation and cliquishness, which quickly leads to the breakdown of trust" (Lehrer 2010).

As Felix Stalder notes in his recent book Digital Solidarity, network theory has taught us that it is possible to assume "that two random people are connected to each other by an average of six nodes [intermediary connections]," and on social networking sites like Facebook, the last measured average distance between users (in 2011) was 4.74 "hops" (2013: 45). Although there are fears that we may become once again isolated from these networks of difference by "filter bubbles" (the filter bubble describes the effect of new algorithms in personalized search that yield results consistent with data already generated about the user, effectively separating them from information contrary to their own opinions), they do make it possible to link materials in Korean, English, and other languages, and to circulate stories and images that cultivate the moral imagination. While the "strongly tied" core of CGWA can handle matters of consensual decision-making for the project's scope and aims, the choice of the "weakly tied" to express solidarity for vulnerable others is partly "a matter of cultivating the imagination ... so as to habituate us into ways of feeling and acting toward them" (Chouliaraki 
2013: 111). This is done skillfully by a suite of CGWA materials visualizing the sounds-of music, of protest, of sorrow-that Cort guitars might-or might be prevented to-make. Music, as a practice and a value, has been a moral-aesthetic force for durable solidarities radiating from the core of CGWA outward to even those nodes of the network that are absent of preexisting commonalities between Cort workers and their potential allies.

In order to piece together the story of Cort guitars I have spent several years drawing on multiple sources but rather than present a history of the company, I want to begin with the stories of the workers at the point when they felt that the company was betraying them. I'll then provide some details on the South Korean and American partnerships before returning to the workers by situating them in the context of the South Korean labour movement.

\section{The Story of Cort Guitar Workers' Action}

Cort Guitar Workers' Action came together in 2007 in support of what turned out to be a seven-year legal battle over the mass firing-actually a mass forced resignation of employees-from Cort's two South Korean plants after their workers attempted to unionize. In a strong tradition of South Korean labour movements, workers had begun to organize as a way to secure better working conditions than the toxic, humiliating, and underpaying situations into which they had long been coerced through a variety of corporate strategies including intimidation, misinformation, false financial reports, and rotating suspensions. Even before then-CEO Park Yung-Ho blackmailed workers into signing a mass resignation agreement, Cort had already prepared to move its operations overseas for cheaper, non-unionized labour in Chinese and Indonesian factories (Cort Action). Since the wrongful dismissal, workers have been engaged in continuous demonstrations against the company. In 2007 a Cort worker set himself on fire in protest, and in 2008 workers conducted a 30-day hunger strike and sitin occupation on a 40-meter electricity tower (Cort Action). These actions mirror something of the duration and intensity of the treatment Cort workers had to endure.

Allegations of a variety of hazardous working conditions go back to 1997. According to one worker: 
The factory was always incredibly noisy and dusty. We worked standing all day long. Most of my coworkers suffer from asthma and swollen legs and have difficulty hearing. My hands became sore from using heavily vibrating grinding machines for a long time. My hands needed surgery, but the company wouldn't recognize my case as a workers compensation case, for which they would be held responsible. (Cort Action)

Complaints of asthma were common because of inadequate safety measures for handling wood "with added preservatives and other treatments such as chromated copper arsenate or pentachlorophenol" (Gan 2014). Workers handled these materials and solvents in windowless, basement rooms, which "were kept unventilated and dry so as to preserve the wood quality of the guitars" instead of using "more advanced and expensive methods such as humidity regulating devices" (Gan 2014). These rooms had "no sunlight whatsoever once you step inside," said Suk-Chun Jang of the Daejeon plant (Cort Action).

In the acoustic guitar factories, Cort production processes use a combination of mechanized, factory line, and highly skilled hand labour (Cort Acoustic Guitar Factory Tour Video 2011). Certain processes are highly automated, like shaping the neck blanks, cutting and sanding the soundboard, coating the instrument with sealant, and cutting the slots for the fingerboard inlay designs, the latter of which is done by a compact CNC machine. Tasks like inlaying the Cort logo, inserting the rosette around the sound hole, arranging the bracing behind the soundboard, installing the bridge, and quality testing are done by specially trained workers. In one of the CGWA documentary video clips, one worker points to her right wrist and asks:

Can you see the lump poking out of my wrist? This is from repeatedly making scooping motions with the sawing knife. The doctor said the joint fluid in my wrist has built up from the heavy workload. The fluid was extracted but this never stopped the lump from growing, and I have been suffering from this painful wrist problem ever since. (Cort Action)

Not only did workers sustain injury and disease without compensation, but the company actually forced workers to take the blame for their own suffering. One worker remembers a colleague who had "worked at the painting process for 25 years and suffered from bronchitis. One day, when he lost consciousness during working, the 
managing staff even demanded for him to write a letter of resignation during hospitalization" (Cort Action). This incident took place amidst a pattern of workers being pressured to start 30 to 50 minutes before official working hours, being prevented from taking even the two 15-minute breaks mandated by Korean labour law, and receiving no overtime allowance. These conditions worsened in the lead-up to production deadlines, but as Sung-Il Kim of the Incheon plant describes, being called into the factory for "extra duty" was so routine that he and other workers habitually missed out on their own families' lives (Cort Action). "I have no idea how my kids grew up," Kim says, throwing his hand up in a gesture of fed-up anger (Cort Action).

These were not the only indignities that workers faced. Another worker describes how sexism was ingrained in the company culture:

Some supervisors greeted the workers by touching the hips of the women workers every morning. They harassed the pretty women workers by asking them to go out after work and molested those workers they considered ugly with mean behavior. For example, they continually assigned the workers they considered ugly to other production lines before these workers became accustomed to the first line. This mean behavior made them feel crazy. (Cort Action)

The Cort Guitar Fact Sheet distributed by workers online, at music conventions, and at rallies, sums up that "workers labored under sweatshop conditions, making less than $\$ 24$ dollars a day," with "no breaks, no bathroom time," while being "verbally and sexually harassed by managers" (see Fig. 1). 


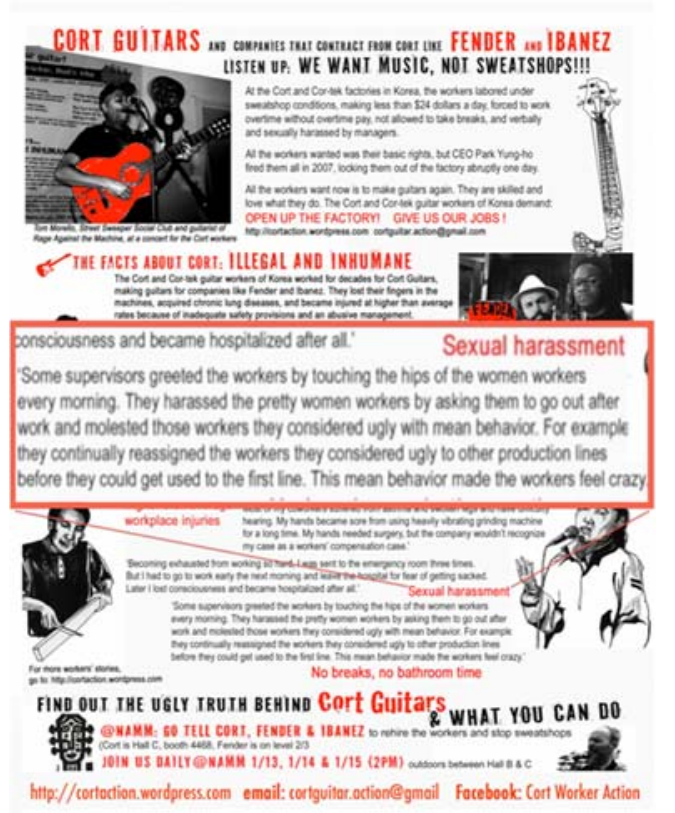

Fig. 1 Cort Guitar Workers' Action fact sheet made for distributing at NAMM 2011. I have modified this fact sheet by enlarging the section about sexual harassment endured by women workers in order to make this information legible within the context of the overall rundown of issues around which Cort/Cor-tek workers have organized. Used with permission from Cort Guitar Workers' Action (http://cortaction.wordpress.com/).

It is not the punishing work culture itself that is a surprise. For South Korean businesses, superior-subordinate relations are constant, grueling tests of loyalty. In the words of a recent article from The Economist, "employees are expected to put in long hours at their desks-more than in any other OECD country, bar Mexico. To leave the office before higher-ups is seen as a betrayal. Late-night drinking sessions with bosses are de rigueur," and it is colleagues, not relatives, that are treated as family (2015). "Bosses are treated as father figures, and colleagues like siblings, joining in each other's family events" (The Economist 2015). The tradeoff, however, is supposed to be lifetime employment for those loyal workers. Despite workers' expectations and despite all the evidence supporting their claims, the court case led ultimately to a crushing disappointment in June 2014 when the Korean Supreme Court held that Cort was within its rights to have terminated the jobs (Kim 2014). CGWA outlived this defeat, however, with the Korean-language CGWA website (http://cortaction.tistory.com/) remaining active until early 2016. The English-language outlets had already been largely inactive since 2011 . My own attempts to reach both Korean- and English-language contact addresses ${ }^{1}$ since 2012 have been largely unsuccessful. This means that for all the attention that can be given by those who picked up on this labour struggle through the international solidarity campaign mounted by the Korean workers, carrying it forward as a 
non-Korean speaker risks speaking for a subject position derived from a limited understanding. Moreover, Cort working conditions already exist in the shadow of the same global neoliberalization which leaves the voices of workers like these "inaudible in the post-national public sphere" (Chouliaraki 2013: 110). Inaudible, that is, insofar as the views of subaltern counterpublics like CGWA-style movements do or don't get constituted into "public opinion" based on where boundaries are drawn around the public and the private, and whether a national-territorial understanding of publicity is assumed or challenged (Fraser 2007a). So how to avoid “misframing" this public conversation (Fraser 2007b), with talk that reproduces "the historical divide between the West and 'the rest' as a discursive act of the power by which the West excludes or marginalizes 'the rest' (Chouliaraki 2013: 110)? Doing so requires contextualizing the struggle of the Cort workers within the broader context of multinational corporate connections brokered, particularly with the U.S. ${ }^{2}$

\section{You and I: Jack Westheimer and Park Yung-Ho Go Into Business}

The Cort and Cor-tek companies (which produce electric and acoustic guitars, respectively) grew out of a business partnership between American Jack Westheimer and South Korean businessman Park Yung-Ho in 1973. Westheimer originally wanted to import Japanese guitars to America, where most guitar manufacturers operated, but instead set up a corporation with Park called Yoo-Ah ("You and I"). In the 1950s, Westheimer and a former boss decided to capitalize on Americans' burgeoning interest in Caribbean music by importing hand-tunable bongos made by Pearl in Japan. A booming interest in guitars was not far behind, and so Westheimer invested money in Japanese guitar makers to secure an improved product for import to the U.S. In the 1970s manufacturing in Japan became increasingly expensive and so Westheimer expanded his operations to include South Korea as a source for his guitars (Wright 1999). It is this model of perpetual foreign expansion that Park would follow in moving operations to China and Indonesia when South Korean Cort workers eventually organized a collective bargaining structure. 
In an interview with Westheimer for Vintage Guitar Magazine, Michael Wright (1999) reports “it was

Westheimer who, along with folks like Jerry Freed and Tommy Moore, brought Korea to the point where today more than half of all guitars made in the world come from that Asian peninsula." But the interventions of these businessmen were only possible insofar as South Korea in the 1960s and 1970s had experienced rapid economic growth in terms of modern industry, and with it, a burgeoning labour movement. Liberal democratic transformation was also afoot, with political democratization taking place in 1987. Under these conditions, from labour-repressive authoritarian rule to post-democratization, South Korean labour politics have had a dynamic history. They are often seen as militant and confrontational, given to public demonstration more than other socalled "Asian Tiger" economies like that of Taiwan (Lee 2011). The first fully democratic trade union in the history of Korea was formed by women garment and textile workers in the 1970s (Chun 2003). Its story was one of both betrayal within the ranks as well as self-sacrifice (the self-immolation of one woman's brother), and also of synergy between state-directed violence and long histories of gendered oppression. It was in the following decade that Cort workers began trying to develop a union as a way to improve shameful working conditions and low wages, but they nonetheless faced intensified corporate violence at every step. In 1987 workers at the Incheon plant formed a union which was broken up with the justification that the company was "going under" (Cort Action). In spite of accounting evidence to the contrary, the company maintained its claim to financial precarity through 1988, firing around 50 workers to "save costs.” In 1991, a "union-free" Cor-tek factory opened in Daejeon. According to the CGWA website, in 1992 Cort stopped "adding manufacturing capacity in Korea and [began] to search for new production sites abroad, in part due to union activity." Government neoliberal reforms and "business-driven labour flexibilization" (Lee \& Yi 2012: 476) grew across South Korea in the later 1990s causing labour markets to fragment and non-regular workforces to swell. The CGWA site elaborates that from 1997 to 2006 Cort employees were "fired in groups as remaining workers [trained] new Chinese and Indonesian workers." Throughout the following year, Cor-tek shut down its Daejeon plant and dismissed all employees at the Incheon plant. In the documentary made by Cort workers after their mass firing, one worker, Myung-Hee Choi, explains that the only communication the locked-out workers received was a memo stipulating that if workers would sign their own resignation, they would be eligible for 
some form of severance wages or retirement packages ("Ugly Truth, pt. 1" 2010). But if they refused to corroborate the appearance of a consenting shut down, not only would there be no monetary compensation, but Park would use his clout in the business world to make sure that none of the workers got hired anywhere else ever again ("Ugly Truth, pt. 1" 2010). In the video, Choi describes feeling humiliated, unable to save face, but without an alternative; coerced, in other words, into submission to a company for which physical and psychological abuse constituted standard operating procedures even on a normal day. Choi, holding a guitar, gestures to the lacquered wood surface of its soundboard and tells her interviewer "press this, the tears will drip out. Not only mine, but the tears people shed on here at each manufacturing step. Press here, the tears will pour out” (“Ugly Truth, pt. 1”2010).

As the Cort story developed into the $21^{\text {st }}$ century, it was against the backdrop of the South Korean labour movement, which remained in flux. While union density and social influence of unions have decreased since the labour movement heyday in the early 1990s, over the past two decades there has been a trend away from enterprise unionism and toward industry unionism. One of the greatest achievements of this tactic has been to avoid the weakening of bargaining leverage felt by decentralized bargaining systems like those that are more popular in Western countries (Lee \& Yi 2012). It is possible to see the logics of this industry unionism-namely “"organizing' the unorganized" and coping with the "fracturing of workers' collectivism" (Lee \& Yi 2012: 477)-reflected in the CGWA bid to consolidate the reforming energies of guitar workers, professional musicians, fans, and others tied in various ways to the music industry broadly. This has entailed further strategy on CGWA's part with respect to who is to be called on as allies, and who is to be held up for critique.

Allies have been labour groups in Japan, Italy, Germany, and, especially, the U.S. (CGWA was able to build solidarity with other Korean unions as well, and additionally on the domestic front, according to Cort Action, "musicians and cultural activists in South Korea have supported Cort workers by holding a monthly concert in Hongdae, holding one-[person] protests, and putting together summer rock festivals to publicize their struggle for reinstatement"3). In addition to labour groups, CGWA connected with instrument makers by travelling 
directly to the two biggest annual trade shows in the world, Musikmesse (Frankfurt, Germany), and the National Association of Music and Merchants (NAMM) trade show (Anaheim, U.S.). Through the latter, CGWA marshaled the presence of prominent artists like Ozomatli, Boots Riley, Zack de la Rocha, Steeve Noonan, and those associated with social justice group Axis of Justice, who have taken up their cause. Under the aegis of their social justice organization Axis of Justice, Morello and Tankian (of Rage Against the Machine, and System of a Down fame, respectively), contacted American guitar brands like Fender, Gibson, and Ibanez, for whom Cort/Cor-Tek manufactures instruments, to inform them of the labour dispute and urge them to voice their outrage to the Cort/Cor-Tek Guitars and Basses company. At NAMM, CGWA also "gathered the support and commitment of local unions and labor organizations, from AFL-CIO United Steel Workers Local 675 and UNITE HERE Local 11 [to] the Orange County Labor Federation" and the Koreatown Immigrant Workers Alliance (KIWA).

It has been instrument manufacturers, rather than consumers or industry partners, that CGWA has critiqued, and this may be a further factor in avoiding in-fighting among its weak ties. The "call-out culture" of online progressive communities often creates boundaries of who's in and who's out, alienating those who are sympathetic to the cause but who have failed in signaling their progressive commitments with the appropriate language and terminology (Ahmad 2015). Take the CGWA relationship with NAMM, for instance. In a 2006 interview with Westheimer, NAMM praised the way he "pioneered several aspects of commerce with China long before it was a common place for musical instrument manufacturing on a global scale," eliding concerns about outsourcing and the temptation to use sweatshop labour that have become part of even the popular discourse about offshore mass production (which itself, at times, exposes currents of xenophobia about keeping jobs "at home"). This interview came just a year before Cort labour controversies began circulating publicly and four years before Cort workers actually traveled to the NAMM show in Anaheim. Their presence there forced the organization to witness another side of the businessman's "American Dream" story they had been eager to promote, but CGWA used the opportunity to shame only Cort and its South Korean founder Park Yung-ho. 
Interestingly, Westheimer's name is absent in the South Korean workers' discourse. Only Park is parodied and criticized (see Fig. 2). There may be a few reasons for this. One is that in terms of the South Korean business world, he is the one who ultimately broke loyalty to the workers. Another, related, is the popular perception that collusion between big Korean businesses (chaebols) and politics is the fundamental cause of political corruption in South Korea (Lee 2004). (Chaebol, meaning "wealth clan," refers to family-owned businesses that have become global conglomerates. Chaebol were mainly established during Japanese rule of the peninsula [191045] "in the working style of Japan's pre-war zaibatsu, huge industrial companies; many chaebol founders were also educated in Japan, and their successors still have connections there" [The Economist 2015]). Street protest against such corruption is normal to everyday life in the country. But the politics of accountability for U.S. businesses, rather than South Korean ones, are therefore different. Although the U.S. has been an important economic partner, foreign businesses don't represent quite the same flavour of political concerns that chaebols do, and street protests perhaps don't seem to speak as loudly to corporate figures who are not physically present within the country. There has, however, been a widespread anti-Americanism movement within the country since the 1980s after the U.S. not only failed to support the counterforce of the violent military regime of Chun Doo-Hwan, but actually hosted Chun and promised more economic supports to his government despite it having slaughtered thousands of civilian protestors (Park 2009). Though a bilateral alliance was formed between South Korea and the U.S. after the end of WWII and bonds were forged by fighting together in the Korean War, South Korean perceptions of American unilateralism have grown since the early 2000s (Steinberg 2005). Negative sentiments have been strongest among Korean youth who do not harbour the same "gratitude... for the extensive support the U.S. has provided South Korea over the last half century" as their parents' and grandparents' generations do (Lee 2004, 16). There is likewise another strain of anti-Americanism based on economic complaints, ranging from complaints including American materialism, to the more specific grievance about the U.S. pressuring South Korea to open its agricultural markets, to the charge that American-influenced thinkers were to blame for the Korean financial crisis of 1997 (Park 2009, 56). ${ }^{4}$ 
Still another reason why Park and not Westheimer has been held up for critique may be related to the fact that many transnational corporations have found it lucrative to put local faces to international brands, making it easy to deflect the blame in labour disputes to what is essentially a decoy for a much larger problem. Along with the practice of giving workers contradictory messages, this strategy promotes horizontal hostility-redirecting tensions away from those who have authorized unfair employment conditions into coworker relationships-and distracts from studying up even higher, to contextualize local struggles in the flows of transnational capital and ideological hegemonies. The English-language CGWA website quotes one worker who remembers that because of managers' uneven treatment of employees "there was always so much jealousy and competition among coworkers. It was like a living hell." Workers who were willing to distance themselves from collective organizing were favoured with pay increases. "The company discriminated among workers by paying them differently, even to those on the same production line," one worker explains. "After raising these persons' wages, the managing staff ordered them to keep this a secret from their coworkers. Every morning meeting, they always warn them to be careful not to disclose the secret" (Cort Action). Meanwhile, those who spoke up for their rights were humiliated and undermined by being transferred to a different line or by being replaced. "It's like this," says Hye-Soon Shin from the Daejeon plant, "when I returned from my rotation post after three months, someone else had already filled in my original place" (Cort Action).

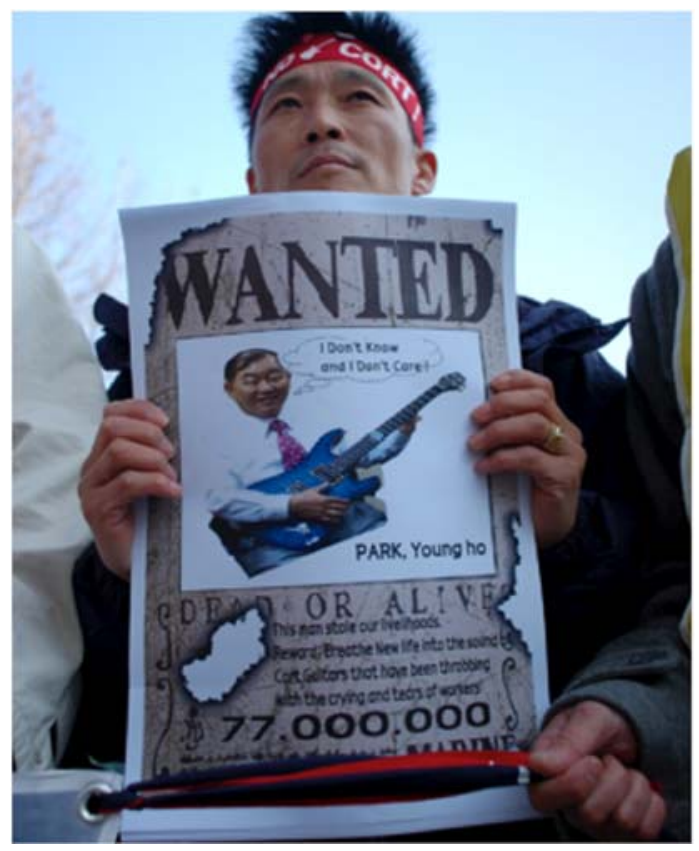


Fig. 2 Photograph of a Cort worker at Frankfurt's Musikmesse in 2009 holding a "wanted dead or alive" poster with a picture of Cort/Cor-tek CEO Park Yung-Ho. Park's speech bubble says “I don't know and I don't care!" The poster text reads: "This man stole our livelihoods. Reward: Breathe new life into the sound of Cort Guitars that have been throbbing with the crying and tears of workers." Used with permission from Cort Guitar Workers' Action (http://cortaction.wordpress.com/).

Cort's practice of bringing in new hires from China and Indonesia for existing workers to train under the pretense of production expansion, then firing the South Korean workers once the new non-unionized labour force was trained, has been another way to divert workers' hostilities into the competition among them. DongHo Lee of the Incheon plant explains: "I thought that they were building factories abroad because the company was doing well. So when they brought in the Indonesian workers for the training workshop, I taught them the works, was really friendly to them. Now I realize that I've been stabbed in the back" ("Ugly Truth, pt. 1" 2010). Lee's words allude to the possibility that such deception also exacerbates national and racial tensions between workers belonging to competing East Asian economies. There are substantial interstate challenges in the region, including the North Korean threat, China’s growth as a military power, tensions between China and Taiwan, and disputes related to the East China Sea and the South China Sea. Pragmatic economic considerations and even the facts of cultural diffusion are entwined with these other challenges for development in the Asia-Pacific region. For instance, as Lee points out in a 2004 report on "The Transformation of South Korean Politics," though such practicalities may prevail over ideological or political concerns in relations between South Korea and, say, Japan, anti-Japanese feelings that are tied up with colonial history remain prevalent across generations, and South Korean industries are vigilant about their vulnerability to competition from superior Japanese goods. In the case of South Korean relations with China (where some Cort manufacturing moved), though the two have an unusually harmonious relationship with respect to trade and also cultural influences, tensions are unavoidable as "the industrial economic relations between the two countries is changing from vertical complementar[it]y to horizontal specialization and competition" (Yoon 2017). With respect to Indonesia (where the rest of Cort's operations moved), though there is a certain parallelism between them as two middle powers with a certain capital complementarity, there are wide cultural divides between their very different populations - the South Korean one that values its ethnic homogeneity, and the heterogeneous Indonesian one. ${ }^{5}$ 
Development, broadly construed, in terms of nation-building, industrial modernization, and political-economic integration into globalizing markets entails both close cooperation and competition in this region. It would seem, however, that the complexity only grows when these macro-level dynamics attempt to be mapped onto the smaller scale of CGWA. It is notable that while CGWA doesn't appear to have mobilized labour groups from Indonesia and China (the latter of which would be near impossible since China specifically censors its Internet to prevent such mobilization), one of the three countries with which the movement is primarily networked, other than South Korea and the U.S., is Japan. On a list of CGWA campaign endorsers, three separate ones are Japanese. There is a special email address to contact to join CGWA in Japan. Japanese labour organizers have hosted Cort workers at their own events in Japan, including the Yokohama Music Fair 2009 and CREAM International Festival for Arts and Media 2009. They have also been welcomed at music festivals, like Fuji Rock 2010. Japanese artists have contributed visual materials such as prints for posters and banners for use in the CGWA campaign. In English-language materials, the history of the South Korea-Japan relationship that makes this solidarity unlikely goes unmentioned. Instead, it is a matter of communicating "across language barriers" that CGWA emphasizes-a problem with a solution to be found readily in shared appreciation for music and the labour that goes into it.

\section{Posters and Protest Songs: Creative CGWA Interventions}

CGWA members have presented themselves both as labourers in a global economy and as artists and music lovers, establishing common concerns with other workers and creators through protests involving music and visual art. Their project is not just activism, nor certainly is it only about awareness, nor is CGWA calling for aid or development assistance-it is a proclamation of "international solidarity" (Cort Action) based on an assumption that the cause is a common one:

Cort Guitars relies on the global market for its profits, beyond Korean borders. That is why the struggle of the Korean workers cannot take place in Korea alone, but must be joined by anyone who believes that music cannot be made under terrible conditions, and that workers everywhere, whether in Korea or anywhere else, deserve to be treated with dignity. (Cort Action) 
Solidarity, wrote David Featherstone (2012: 5), "has rarely been the subject of sustained theorization, reflection or investigation," but it can be defined as "a relation forged through political struggle which seeks to challenge forms of oppression." The stance of CGWA is perhaps better described as taking the relation to exist already, but the struggle as giving it specific form and demonstrating its strength. Analyzing a selection of the art and cultural objects produced by Cort workers and CGWA affiliates will illustrate the significance of the CGWA claim that:

The struggle for the Korean workers at Cort/Cor-tek knows no borders, and needs the support of people around the world, including musicians, activists, journalists, artists, cultural activists and anyone who believes that workers and artists need each other and should fight together for the right to make music that means something, that calls for justice ... Because we believe that there can be no music without the workers who make the instruments.

These words and the images they frame in the CGWA English-language blog try to make it impossible in the mind of the reader to separate the Cort workers from the instruments they make and from the music the two make together. For CGWA, the struggle is not just a labour issue, but one involving art as a political tool and a common good. Wage labour is alloyed with the concept of labour as a creative human enterprise. Allies all "around the world" are invited on this level, regardless of their commitments or indifference to a whole host of political-economic realities about manufacturing in a global market. The passage above, after a break filled by an image of unfinished guitars with mute, blank soundboards, goes on to invite specific consumer action:

What do [the workers] want? They want Cort/ Cor-tek to re-open the factories and let them regain their livelihoods, their dignity, and their identity as guitar workers.

For anyone considering buying a Cort guitar or bass, please reconsider.

Aren't people worth more than guitars?

Even in this challenge to readers to treat people as ends-in-themselves rather than means to their consumer desires, the Cort workers' personal identities are inseparable from guitars. The photo punctuating these two excerpts is from a photo series called An Abandoned Factory: Gallery of Cor-tek factory in Daejeon, Korea by Noh Soon Taek. It exposes the interior of defunct factory buildings chock full of orderly stacks and rows of 
guitar parts receding into dark corners and corridors that are now hauntingly devoid of human life. But in other visuals, human life reinhabits the guitars from which CGWA imagines it cannot really be unentwined.

There are several editions of CGWA campaign posters that use traditional and digital printmaking techniques to creatively imagine, rather than represent, human/guitar relations. Bold colours and text mix with stylized depictions of guitars to further identify workers with their instruments-in some cases, anthropomorphizing the guitars to appear as though either defying or grieving their loss of place. A woodcut series by Cort worker Yoon Yeop features a black upside-down guitar whose sound hole is the angry face of a worker clad in a respirator. Around each side of the waist of the guitar comes a hand, one clasping a saw and the other a hammer. Beside the rebellious guitar lies a column of red Korean characters saying: "We want to work!" Another series is by a Japanese artist working under the moniker NEO DADAKKO, who created a simple computer graphic of a light brown guitar styled as a face whose sound hole is an open frowning mouth with two small eyes above, and the words "No Cort" spelled from the broken strings sprung from their tuning keys (see Fig. 3). The dissident guitar sits atop rounded cartoon shoulders, its message a blend of the human voice of Cort workers and the voice of the guitar's music, which, for CGWA, speaks a universal language of artistic freedom.

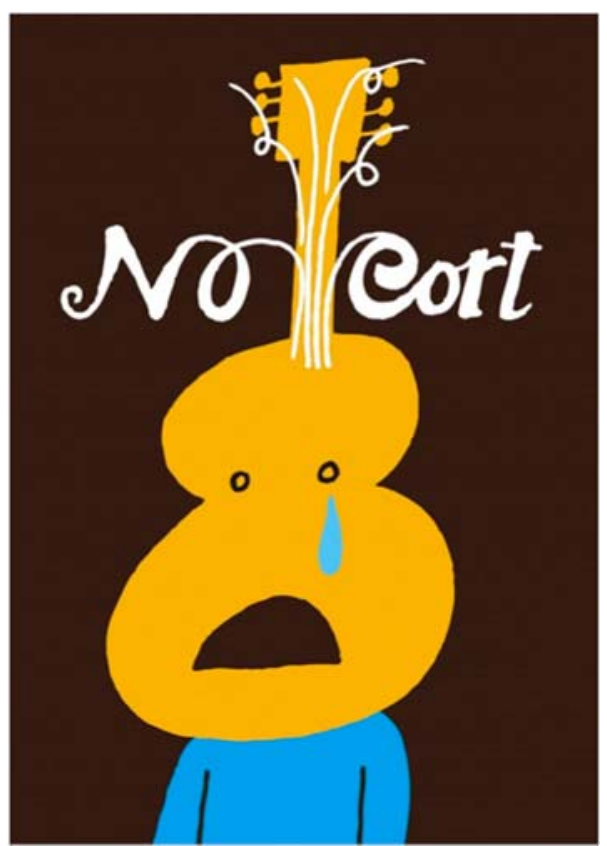

Fig. 3 "No CORT" campaign poster graphic, designed by Japanese artist and activist Neo Daddakko during the week of actions in Tokyo and Yokohama. Used with permission of artist 
(http://neodadakko.blogspot.ca/2009/11/no-cort.html).

Other CGWA campaign posters depict people and their guitars as separate entities in a variety of different relationships to one another. One banner illustrates a dejected chibi style girl holding a guitar that sheds teardrops down the length of it. Another poster portrays a faceless worker impaled through the chest by the headstock of a detailed black and white Fender-style guitar. As vibrant red blood pools around the solid black shape of his prone body, his worker's hammer and saw have fallen out of grasp. Blood also drips off the letter "C" in the word "Cort" emblazoned in red across the guitar's bass bout (lower body) (see Fig. 4). In these images, it is as if music itself has disappointed or betrayed those who make and love it. Visually, these images are effective in part because the iconic shape of the guitar speaks to music lovers across so many different genres. Conceptually, they are powerful because they mobilize the contrast between the expected connotation of music as a vector of self-expression, and its opposite; music perverted into a force for aggression, turned back in on the workers themselves. In this case the guitar indeed remains literally a part of the human body, but an unusable and painful part that needs to be reordered back into harmony with the worker, so that it may become once again an instrument of music, rather than of suffering.

Workers march with these images, play shows with prints pinned to them like aprons, and spread them online. They have traveled to the sites of all their various actions, which have been selected, notably in the case of NAMM (Anaheim) and Musikmesse (Frankfurt), because they are the national and international hubs for commercial companies, distributors, affiliates and manufacturers, as well as artists who are famous enough to be endorsed by exhibitors at these trade-only business shows. These constituencies are involved with the operations and standards of the music industry itself in ways that fans and even artists are not. So, while CGWA uses the universal language of "anyone" "around the world," its major national-institutional points of contact are where these constituencies are. Still, elsewhere CGWA visuals have served as props for new supporters to hold in photo opportunities that expand the visual presence of the "No Cort" campaign across different music scenes. CGWA has also invited anyone to take a picture "of yourself-of a musician friend, a music lover who cares about worker rights" (Cort Action) holding a sign that says "No Cort," "Shame on Fender" or "Fender 
Watch." There are dozens of such photos to be found online, but the vast majority are housed on CGWA's own pages, while others are scattered on the blogs of some South Korean labour groups and American musicians or producers. These one-off references tend to occur in relation to a specific protest action. In trying to identify the audiences to which CGWA content has spread and how they were affected, it is notable that, as SalahEldeen and Nelson (2012) have shown in relation to content linked through Twitter, up to $11 \%$ of the online content referenced by social media has been lost and only $20 \%$ archived one year after an event. Further, the limited coverage achieved by CGWA materials is unsurprising when you consider that their largest events are trade shows where awareness might be raised among industry members, whose scope and commercial priorities might mitigate against staking a public claim about the labour dispute. In journalism, the only sympathetic coverage seems to be occasional updates on the court case from the South Korean independent newspaper The Hankyoreh since 2009, Pressian (a South Korean political news website), OhmyNews (a citizen journalism site), and a 2010 video segment on the Korean Broadcasting Service News following up on how some workers were earning a living three years after the final closure. Korean media including Donga Daily and Korean Economic Daily reported in 2008 and 2014 respectively that the workers' strikes and protests led to the closures of the Cort/Cor-tek factories (Kim 2016). (And as recently as 2015, the Cort/Cor-tek closures were held up by conservative Saenuri Party chief Kim Museong at the National Assembly as an example of how unions force "healthy, high profit companies" to close their doors [Kim 2016]). 


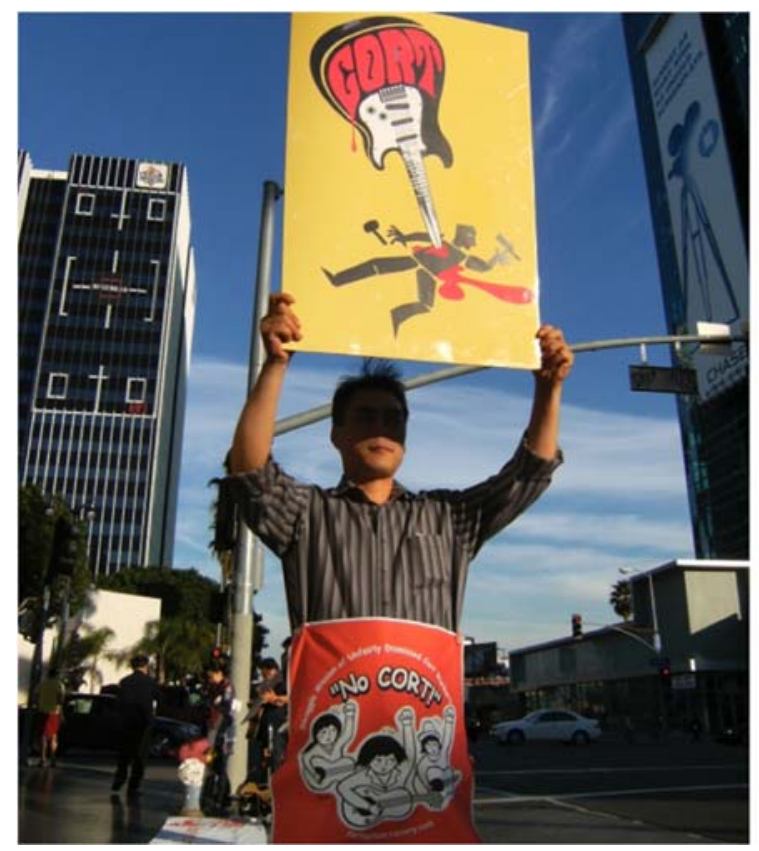

Fig. 4 Photograph of a Cort worker at a protest wearing a "No CORT" campaign poster and holding a print depicting a Cort guitar worker being skewered by the instrument the worker made. The text of the poster being worn like an apron says "Struggle Mission of Unfairly Dismissed Cort Workers" and gives the URL of the Korean-language CGWA blog (http://cortaction.tistory.com/). Used with permission from Cort Guitar Workers' Action (http://cortaction.wordpress.com/).

Cort workers also made a documentary, which is posted in three parts on YouTube under the title "The Ugly Truth Behind Cort Guitars.” This documentary includes footage of a jazzy song whose introduction goes: "come together, labourers of the world/ the world belongs to us/ not to Park of Cor-tek/ never to Gun-Hee Lee of Samsung/ we already know that the world exists for us all" ("Ugly Truth, pt. 2" 2010). An excerpt of the first video has over 100,000 views, while the full-length version has nearly 60,000, the second part has around 15,000 , and the third part has close to 9,000 views. The limited nature of YouTube metadata makes it hard to know where the majority of these people are from, but among the approximately 250 comments on them (combined), nearly all are in English. Some note their location, including: America, Korea, Canada, Russia, New Zealand, Brazil. In content, they appear to be fairly divided between vowing never again to support Cort and fighting with other commenters about the appropriate stance to take in relation to global capitalism. Another English-subtitled documentary-listed in some places as Guitar Story (2009) and in others as Dream Factory-was made by filmmaker Kim Sung-kyun. It was selected for distribution support by the Asia Cinema Fund at the 2010 Pusan International Film Festival, traveled that year to NAMM with Cort workers, and then 
screened at film festivals in Chicago (CIMMfest) and Toronto (NXNE) the following year (to mixed reviews: “There's a great documentary to be made out of th[e] story, but sadly Dream Factory isn't it. Director Kim Sung-kyun's draggy, muddled take on the ongoing situation plays like clumsy agitprop" [Wilner 2011]).

The breadth of media used and the inclusive language of workers' appeals to consumers and musicians outside of Korea's borders speaks to building "a broad-based coalition" (Cort Action). This, to use the words of David Featherstone, is an "active creation of new ways of relating" (2012: 5). Indeed, CGWA has received in-depth attention in an article posted on the website of the Global Ethics Network, been contextualized alongside similar Korean labour struggles on the Solidarity Stories site, and picked up through the Axis of Justice angle on the People's World site and the major UK music outlet Music Radar. Axis, who listened to Cort workers' needs and broadcasted their requests to re-post campaign material, to write Park, to boycott Cort products until their jobs were reinstated, and to participate in musical happenings and other forms of protest, likewise drew on the language of creative freedom. In an interview about a planned protest at NAMM 2010, Morello was emphatic: “Guitars should be a means to liberation, not exploitation. I fully support the Korean workers' demands for justice in the workplace" (qtd. in Bosso 2010). The composition of the coalition raised by CGWA demonstrates "the importance of marginal groups in shaping practices of solidarity," challenging "assumptions that subaltern groups, those subject to diverse forms of oppression, lack the capacity or interest to construct solidarities" (Featherstone 2012: 5). Nonetheless, it has not been part of CGWA strategy to draw attention to all those diverse forms of oppression. Whether deliberate or incidental, CGWA's own materials tend to minimize the role of multinational capitalism in producing different subjectivities-matters of race and geopolitical location go unmentioned. Instead, they emphasize fairness in international economic relationships. They capitalize on the tractability of framing solidarity along the lines of upholding the moral obligations entailed by an aesthetic commitment to music.

In a number of places the CGWA website reiterates that the ultimate goal is for Cort workers to continue the work they have been doing, but under safe conditions and fair wages. In one case, it puts it thus: "The Korean 
guitar workers want to return to the factory and work. Making guitars is their identity and their means of livelihood." The work of these instrument-makers is understood as part of both a personal and professional identity which is universally symbolized by the object of the guitar and the common language it speaks. South Korean workers are compared to workers anywhere else, with little elaboration on differential labour standards globally or why an artisanal craft like that of the luthier has been transformed into sweatshop labour in South Korea, specifically. Their analysis does address class privilege within the South Korean context-Park is held up as an example of obscene wealth and greed-and gender discrimination within Cort, but the larger problem of a multinational corporation selling out its base is not construed in intersectional terms. Indeed, the nature of capitalist development is racialized and discriminatory, the analysis mobilized by Cort workers in their international campaign was about employment conditions in domestic companies, and about the efficacy of their legal system in dealing with massive failures of human rights. Their analysis addresses the international dynamics of this relationship to the extent that economic flows are sped along by American commercial currents, but can be dammed by a globally distributed consumer base:

All American guitar manufacturers and the people that play them should hold Cort accountable for the awful way they have treated their workers. Without us, they go out of business. Simple as that. No one should have their job taken away because they stand up for their rights. (Cort Action)

Yet some of the other oppressions that interlock in the Cort case are gestured to in a 2011 article in Sociarts, "a production company and online community dedicated to socially conscious artists to promote positive social change through the arts and media." Here, mention of anti-immigrant discourse stands as a sort of cipher for racism. The music critic and activist Alexander Billett connects Fender's complicity in Cort's bad behaviour with another scandal-its Arizona headquarters' complicity in creating a hostile environment for documented and undocumented Latino immigrants. He says:

Nobody should play a Fender guitar-at least nobody who cares the least bit about justice in the world. And certainly nobody who calls themselves an ally of immigrant rights or the right to make a decent living. In fact, Fender is guilty not only of crossing the line against one of these causes, but both at the same time. (Billet 2011) 
This kind of intersectional language (Crenshaw 1991) about race and class is less prevalent when CGWA comes up in the online guitar and music discussion forums. There, language around human rights and labour practices tends to take center stage-though some posters have questioned the value of consumer activism in the first place (“if we boycott Cort made products, won't these workers be out of jobs?” [Seymour Duncan User Group Forum 2011]) and some have reasoned that if "they don't like the working conditions, they can get another job. If they CAN'T get another job, then they should be glad to have one at all, or relocate where there are more jobs" (Encyclopaedia Metallum: Metal Archives Message Board 2011).

And although the voices of the Cort workers themselves are only one click away, the fact that communities can be connected by the Internet does not mean they will be connected, at least in such a way that they are participating meaningfully in the same conversation. As Stalder says, "the ability to share information and build extensive social networks is of great, immediate value to most people. Yet, these tools are, of course, equallyarguably even primarily-constructed to create profits for investors who financed it and thus shaped it from the beginning," which means that many of these conversations go on in parallel in kinds of venues-from Facebook to discussion boards on music retailers' websites-where there is little accountability to the original message and the people who developed it (2013: 47). So while CGWA proclaims that "music is a global language that crosses borders" (Cort Action), the cosmopolitanism of the movement should not be allowed to disguise the fact that "cross-border alliances against corporate injustices" (Mohanty 2003: 249) may be impeded by an Anglo hegemony that makes it harder for non- or non-native English speakers to be heard internationally as political actors. For instance, the political efficacy of the creative alliance with Axis, compared to the German trade unionists at Musikmesse, the Mexico-based workers employed by Fender, and KIWA, has been disproportionate. CGWA has been shrewd in mobilizing the Anglophone U.S.-based Axis to hedge this very liability-especially since maintaining equal levels of bilingual coverage has not been feasible.

One Facebook page called Cort Worker ACTION, which is registered as a non-profit organization, last had activity in late 2013. Another, designated as a community page and called No Workers, No Music! No Music, 
No Life! tapered off in Fall 2012. At the time of writing, a public group called Friends of Cort/Cor-tek Workers

(formerly No Cort) remains highly active with around 1500 members posting in Korean. This was the communication tool that enabled me to learn that the English-language blog had gone dormant because the organizer who cared for it could not care for it any longer. Messages to the other two other CGWA Facebook accounts and the Axis of Justice Facebook account yielded no replies. Although the CGWA Twitter account @ CortAction became inactive in 2011, in Fall 2014 under my own account, I tried the following tweet: "Korean Supreme Court recently ruled against Cor-Tek workers-Is anyone still using \#nocort \#cortaction for @CortAction campaign?” It failed to stimulate any replies or retweets. Around the same time I emailed a query to an administrator of Solidarity Stories, a blog of the International Strategy Center, who regretted to inform me that they did not know anyone in the Cort Guitar struggle, nor did they know any English speakers who could be contacted about it. However, inquiring about new developments after the Supreme Court disappointment, I received a response on the No Cort group's public "wall” from Miru Lee ${ }^{6}$ a member who was able to write in both English and Korean. She explained that people were still pursuing legal action not only on the labour issue, but also about the factories being sold, torn down, and rebuilt in other countries. Even now, workers stay in front of the old factory building in Incheon performing protest songs to increase public awareness locally. Evidently, dedication to the Cort case has remained as deep as it was in 2010 when the "Ugly Truth About Cort Guitars" workers' documentary depicted Myung-Hee Choi declaring: "If I retreat, I'm failing the whole community. So I have to fight and win. I have to fight for my children so that when they become workers, they won't be treated like I did" (Cort Action). But what is also evident is that the effort of maintaining activity outside of Korea and carrying on the conversation in other languages has not yielded rewards enough to justify continuing to expend it.

For the reasons I have shown, it is difficult to get an accurate read on the vitality and scope of CGWA as an international solidarity enterprise. As the Cort workers' story remains unresolved, Cort's four enterprises, now in Indonesia and China, provide guitars and parts to almost every major American guitar brand. Westheimer and Park no longer play the same roles. Just three years ago, after a 40-year distribution relationship with Cort, the 
Westheimer Corporation announced it was ending the distribution agreement. Cort guitars are now distributed in the U.S. by Davitt \& Hanser (Wissmuller 2014). Park's son has become the company CEO. In the "Ugly Truth" documentary in 2010, In-Geun Lee ${ }^{1}$ of the Daejeon plant had told documentary-makers, "our situation remains in the dark. Nobody cares. Society is cruel not to care" ("Ugly Truth, pt. 1"). Five years later, the only Korean member of CGWA I was able to get in touch with (over one of three "No Cort" Facebook pages) echoed a milder version of this sentiment: "some people expressed their attention about Cort from outside Korea, but not that many." In 2017, CGWA members are still engaged in collective action, though the most recent example was targeted above the company level and aimed, along with other artists and cultural figures, at the national administration of recently-impeached formed President Park Geun-hye, who they accused of oppressing artists. Undoubtedly, it is an important chapter in South Korea's history of radical labour activism, but because of its significant digital dimension it emphasizes not just the dilemmas associated with the vastly uneven relations of international solidarity movements, but also of digital solidarity or online activism more broadly. The unique effects of weak ties are the positive sides to the exigencies of information overload, the negative sides of which are the attenuation of attention and political will by (among other things) an essentially endless list of causes that are easily exposed via the Internet.

\section{Conclusion}

As I began researching Cort guitars and CGWA in 2012, I mentioned the Cort labour scandal, which I found easily through an online search, to a colleague who teaches guitar at a local music school. It was news to him, and to the music school's owner, too. When I called a local music store, a representative for the instrument retailer informed me that the store carried Cort guitars about 10 years ago, but then replaced them with a similar Canadian line called Sigma. These dealer relationships are franchised, so music stores have to pay the company an annual fee to carry their products. Every shop has a proprietary relationship with different brands, said the man who answered the phone at another music store. In Canada there is only one Cort wholesale distributor, Coast Music in Québec. Speaking with their product manager, I learned that thousands of acoustics, electrics, and basses are sold all across Canada each year, and the reputation I had heard about Corts-a "good bang for 
your buck"-remains current. While Cort produces some entry-level and some high-end instruments, it mainly targets mid-market consumers, and as is borne out by the Canadian guitar forums online, these instruments are favoured as workhorses (sometimes lovingly known as "beaters") in the collections of both amateurs and professional musicians. Only one shop local to me holds the right to sell Cort guitars, which usually cost around \$200-\$500 a piece, with a couple of instruments coming in above that price range. The instrument retailer representative on the phone wondered what piqued my interest in Cort specifically and I told him I owned one and loved the sound but was unsure if Canadian dealers carried them anymore because of the corporate labour scandals. He said his shop carried products by Ibanez, which contracts Cort to build lower-priced guitars that still have the Ibanez brand on them, but he had no idea about the Cort controversy. He followed up by recommending me some Fender electric-acoustic products-which, considering that Cort also produces for Fender, means that some of those substitute instruments may technically be Corts anyhow. When Cort produces lines for much more expensive brands like Fender, the guitars are only prominently labeled with the high-end brand name, making it difficult to determine whether Cort's unethical labour practices were implicated in the product. Cort relies on this confusion as well as on the fact that consumer activism is available in many cases only to the economically advantaged, meaning that even with the knowledge of corporate wrongdoing, the odds are in favour of low price to win out over ethical considerations. According to the person at the store that does sell Corts-who likewise had no idea about the company's labour history-there is "an endless stream of them" to be had, their availability apparently unstaunched by "No Cort!" boycotting. "As far as I know," he said, "when we need them we can just order them." The easy availability of this product is a stark contrast to the stories of pain, broken families, disfigurement, and death told by the workers who make it.

For the international elements of Cort Guitar Workers Action, online communications have been essential. As a coalition formed in part through a weak digital network, CGWA "relies neither on the market, where price signals perform important co-ordinating functions horizontally ... nor on public and private bureaucracies, where commands facilitate vertical co-ordination," but rather on "voluntary co-operation to enhance the use 
value of a shared [informational] resource" (Stalder 2013: 28). Depositing digital artefacts like campaign posters, graphics, blogs, and tweets, in the Internet has given limited non-Korean-language resources an afterlife, and enabled English speakers to pick up the conversation when it has quieted down. Because of this formation, there are some notable discursive silences perforating the predominantly U.S.-based response to the campaign in relation to race and gender. Though the wholesale distributor reported that sales demographics are unknown, it is worthwhile to note that CGWA tends to hail rock music and musicians, wherein the ascendency of white hetero masculinity is well documented (eg. Maus 2011). This has implications for the breadth of the "broad based" coalition aimed at by the movement, especially when factored in with the way that not only the language of globalization is masculinized through the use of gendered metaphors that naturalize "hierarchies required for globalization to succeed" (247), but also the way anti-globalization discourse is masculinized, too. Although "in the anticorporate consumer movements ... and the antisweatshop movements, it is women's labor and their bodies that are most affected as workers ... and consumers/household nurturers," notes Mohanty (2003), "antiglobalization work does not seem to draw on feminist analysis or strategies" (249). To some extent, these factors in workers' oppression have been strategically bracketed, instead of analyzed in their imbrication with issues of class and labour rights, as a way to draw supportive linkages between South Korean workers and affluent Westerners in other branches of the movement. Instead, the language- and positionality-transcending force of music has been conjured to great effect in order to make likeness among potential allies, where perhaps little was evident before.

By paying as much attention as possible to the empirical conditions of the Cort workers, and by consolidating the English-language documentation of their successes and challenges, it is my hope that "drawing attention to such marginalized histories" can add to the store of "usable pasts" in an internationalist working class history (Featherstone 2012: 9). It is important to give what Arat-Koç (2005) calls a "social explanation"-one that historicizes political relations, reveals the coevalness of social actors, and highlights their entanglement in each other's material realities-in order to see beneath the topography of how international solidarity can take shape through weak networks. Namely, it draws our attention to the role of media in "producing imaginations of 
solidarity" that are not accounted for in "rationalist" approaches to "producing meaning about vulnerable others" and inviting the solidarity of the West (Chouliaraki 2013: 111). We see the "performative power of aesthetics ... to use historically specific "topics of suffering"' for moral change and progress (Chouliaraki 2013: 111).

Thanks to the generosity of a bilingual friend, I was able to obtain a translation of the most recent posts to the Korean-language CGWA website. The final update is a poster whose main text reads: The last day of the Loud Noise [a translation of a Korean name for the CGWA protests] is Friday, November 7, [2014]. The Loud Noise started in 2011 and is coming to an end. Please come and join us." Some plots in the Cort story are over, and some will surely continue to unfold. The way forward will place increasingly higher demands on media literacy and may be aided by a formative assessment of the campaign efforts to date, such as the one offered here. Most importantly, for allies, making forward motion means internalizing the notion that the most useful intervention is one that reveals the most complete picture possible. Otherwise, activists are like doctors treating symptoms while leaving the root problem untouched and its etiology a mystery.

\section{References}

Ahmad, Asam. 2015. A Note on Call-Out Culture. Briarpatch Magazine.

https://briarpatchmagazine.com/articles/view/a-note-on-call-out-culture.

Arat-Koç, Sedef. 2005. The Disciplinary Boundaries of Canadian Identity after 9/11: Civilizational Identity, Multiculturalism, and the Challenge of Anti-imperialist Feminism. Social Justice 32(4): 32-49.

Axis of Justice Website. http://axisofjustice.net/.

Billet, Alexander. 2011. Two Good Reasons to Boycott Fender. Sociarts.

http://www.sociarts.com/rebel frequencies/two-good-reasons-boycott-fender.

Bosso, Joe. 2010. Rage’s Tom Morello Leads Protest at NAMM Show. Music Radar. http://www.musicradar.com/news/guitars/rages-tom-morello-leads-protest-at-namm-show-232325/. 
Broadbent, Kaye. 2007. Sisters Organizing in Japan and Korea: The Development of Women-Only Unions. Industrial Relations Journal 38(3): 229-51.

Chen, Yong. 2012. Confucianism as Religion: Controversies and Consequences. Boston: Brill.

Chouliaraki, Lilie. 2013. Mediating Vulnerability: Cosmopolitanism and the Public Sphere. Media, Culture \& Society 35(1): 105-12.

Chun, Soonok. 2003. They are Not Machines: Korean Women Workers and Their Fight for Democratic Trade Unionism in the 1970s. New York: Routledge.

Cort Guitar Workers’ Action Website. http://cortaction.wordpress.com/.

Crenshaw, Kimberlé. 1991. "Mapping the Margins: Intersectionality, Identity Politics, and Violence against Women of Color.” Stanford Law Review 43(6): 1241-99.

Encyclopaedia Metallum: The Metal Archives Message Board. 2011. Boycott Cort Guitars! http://www.metalarchives.com/board/viewtopic.php? $\mathrm{f}=8 \& \mathrm{t}=82064$.

Featherstone, David. 2003. Spatialities of Transnational Resistance to Globalization: The Maps of Grievance of the Inter-continental Caravan. Transactions of the Institute of British Geographers 28(4): 404-21.

—. 2012. Solidarity: Hidden Histories and Geographies of Internationalism. New York: Zed Books.

Fraser, Nancy. 2007. Reframing Justice in a Globalizing World. New Left Review 36: 1-38.

—. Transnationalizing the Public Sphere: On the Legitimacy and Efficacy of Public Opinion in a PostWestphalian World. Theory, Culture \& Society 24(4): 7-30.

Gan, Bryan. 2014. "Press this Guitar and Tears will Pour Forth": A Ballad of Labour Rights in South Korea. Global Ethics Network. http://www.globalethicsnetwork.org/profiles/blogs/press-this-guitar-and-tearswill-pour-forth-a-ballad-of-labour.

García-Herrero, Alicia. 2016. South Korea and Indonesia: A Capital Match. Bruegel. http://bruegel.org/2016/11/south-korea-and-indonesia-a-capital-match/.

Government of Canada. Canada - Korea Relations. http://www.canadainternational.gc.ca/koreacoree/bilateral_relations_bilaterales/index.aspx?lang=eng.

Granovetter, Mark. 1973. The Strength of Weak Ties. The American Journal of Sociology 78(6): 1360-80. 
Ikenberry, G. John, and Michael Mastanduno, Eds. 2003. International Relations Theory and the Asia-Pacific. New York: Columbia University Press.

Kim, Joyce. 2016. The Music and Struggle Must Resonate. International Strategy Center. http://iscenter.or.kr/english/2016/03/09/the-music-and-struggle-must-resonate/.

Kim, Min-kyoung. 2014. 7-year Cor-tek Guitar Workers' Court Struggle Ends. The Hankyoreh. http://www.hani.co.kr/arti/english_edition/e_national/642245.html.

Lee, Byoung-Hoon, and Sanghoon Yi. 2012. Organizational Transformation Towards Industry Unionism in South Korea. Journal of Industrial Relations 54(4): 476-93.

Lee, Namhee. 2007. The Making of Minjung: Democracy and the Politics of Representation in South Korea. Ithaca: Cornell University Press.

Lee, Sook-Jong. 2004. Transformation of South Korean Politics: Implications for U.S.-Korea Relations. Washington: The Brookings Institution. https://www.brookings.edu/wpcontent/uploads/2016/06/lee2004.pdf.

Lee, Yoonkyung. 2011. Militants or Partisans: Labor Unions and Democratic Politics in Korea and Taiwan. Stanford: Stanford University Press.

Lehrer, Jonah. 2010. Weak Ties, Twitter, and Revolution. WIRED. https://www.wired.com/2010/09/weak-tiestwitter-and-revolutions/

Lie, John. 2015. K-Pop: Popular Music, Cultural Amnesia, and Economic Innovation in South Korea. Oakland: University of California Press.

Marlow, Iain. 2015. South Korea's Chaebol Problem. The Globe and Mail. https://beta.theglobeandmail.com/report-on-business/international-business/asian-pacific-business/southkoreas-chaebol-problem/article24116084/?ref=http://www.theglobeandmail.com\&.

Maus, Fred. E. 2011. Music, Gender, and Sexuality. In Martin Clayton, Trevor Herbert, and Richard Middleton, eds. The Cultural Study of Music: A Critical Introduction, 317-29. New York: Routledge.

Milošević-Dordević, and Žeželj. 2017. Civic Activism Online: Making Young People Dormant or More Active in Real Life? Computers in Human Behavior 70: 113-18. 
Mohanty, Chandra Talpade. 2003. Feminism Without Borders: Decolonizing Theory, Practicing Solidarity.

Durham: Duke University Press.

Page, John M. 1994. The East Asian Miracle: An Introduction. World Development 22(4): 615-25.

Park, Seong Won. 2009. The Present and Future of Americanization in South Korea. Journal of Futures Studies 14(1): 51-66.

SalahEldeen, Hany M., and Michael L. Nelson. 2012. Losing My Revolution?: How Many Resources Shared on Social Media Have Been Lost? Theory and Practice of Digital Libraries 7489: 125-37.

Setyawati, Nur Aini. 2005. A Comparison on Indonesian and South Korean Nationalism: A Historical Perspective. Humaniora 17(3): 225-35.

Seymour Duncan User Group Forum. 2011. Thread: Cort/Cor-tek Guitars and their Rebranded Products. http://www.seymourduncan.com/forum/showthread.php?218691-Cort-Cor-tek-guitars-and-theirrebranded-products.

Solidarity Stories Website. Ongoing Campaigns: Labor. http://isckoreamedia.wordpress.com/ongoingcampaigns/.

Stalder, Felix. 2013. Digital Solidarity. Lüneburg: PML Books.

Steinberg, David. I., Ed. 2005. Korean Attitudes Toward the United States: Changing Dynamics. New York: M.E. Sharpe.

The Economist. 2012. The Week Ahead: The Beef Over Trade March 9. http://www.economist.com/blogs/newsbook/2012/03/week-ahead-march-9th-2012.

—. 2015. Corporate Culture in South Korea: Loosening Their Ties.

https://www.economist.com/news/business/21679214-punishing-work-culture-gradually-being-relaxedloosening-their-ties.

The Ugly Truth Behind Cort Guitars 1. 2010. http://www.youtube.com/watch?v=PY5wCAqY$\underline{\text { ek\&feature }=\text { related. }}$.

The Ugly Truth Behind Cort Guitars 2. 2010. http://www.youtube.com/watch?v=7pbKvESThn0. 
The Ugly Truth Behind Cort Guitars 3. 2010.

http://www.youtube.com/watch?v=R01GFdfp8Zs\&feature=related.

Thornton, William. 1998. Korea and East Asian Exceptionalism. Theory Culture Society 15(2): 137-154.

Wee, Sui-Lee and Jeyup S. Kwaak. 2017. China’s Harsh Words Mask a Trade Boom With South Korea. The

New York Times. https://www.nytimes.com/2017/09/29/business/china-south-korea-trade.html?_r=0.

Westheimer, Jack. 18 January 2006. Interview by National Association of Music Merchants.

http://www.namm.org/library/oral-history/jack-westheimer.

Wilner, Norman. 2011. Dream Factory. Now Toronto. https://nowtoronto.com/movies/features/dream-factory/.

Wissmuller, Christian. 2014. Davitt \& Hanser to Distribute Cort Guitars in the U.S. Musical Merchandise

Review. http://mmrmagazine.com/91-upfront/1773-davitt-hanser-to-distribute-cort-guitars-in-the-u-

s.html.

Wright, Michael. 1999. Jack Westheimer: Pioneer of Global Guitarmaking. Vintage Guitar Magazine. http://www.vintageguitar.com/1933/jack-westheimer/.

Yoon, Yung Sil. 2017. Turning Point in Relationship: S. Korea, China Face Growing Competition in Exports. Business Korea. http://businesskorea.co.kr/english/news/industry/19059-turning-point-relationship-skorea-china-face-growing-competition-exports.

Notes

${ }^{1}$ These include the three email addresses-the general English-language one, a contact in Japan, and the Korean contact address.

${ }^{2}$ Canada and Canadians are of course implicated in these geopolitical relationships, though less centrally than the U.S., especially given the history of U.S. military and cultural imperialism in South Korea. In fact, to some extent Canada-Korea relations are shaped by each country's alliances with the U.S. However, friendly relations owe in part to the fact that Canada was among the top three contributors to United Nations Command (UNC) in 
the 1950-53 Korean War, and that Canada remains involved with UN groups dedicated to security on the Korean peninsula. Aside from shared commitments to multilateralism, the two countries have also been significantly involved with each other through bilateral trade, and people-to-people linkages. Notably, Canadians form a large contingent of the foreign teachers who move to Korea to teach English-upwards of 3000 of the approximately 23,000 Canadians living in Korea. For its part, Canada is home to more than 170,000 people of Korean origin (Government of Canada 2015).

${ }^{3}$ It is noteworthy that despite the transnational fandom of K-pop (South Korean pop music performed by "idol" groups who sing catchy songs and do choreographed dances in coordinated outfits), CGWA has not capitalized on the "frenzied internationalization of South Korean popular culture" (I thank an anonymous reviewer for this evocative wording and for raising the question of K-pop's relevance). CGWA repeatedly invokes the genres of "rock" and "indie" music, but not pop, Korean or otherwise. I suspect that this might have to do with the way K-pop's association with 'the ready-made vocabulary of Korean tradition ... or 'national essence' $[k u k s u] \ldots$ Confucian culture, and other mythemes of contemporary South Korea" (Lie 2015: 3) that might work against the serious and international image cultivated by CGWA. Of course, this is a matter best fleshed out through qualitative interview and participant observation research with the people of CGWA themselves.

${ }^{4}$ Evidently, the politics of accountability in South Korea for U.S. and South Korean businesses are complex, but as a full examination is outside the scope of this paper, see Steinberg (2005) for a start.

${ }^{5}$ It would take far more space than is available here to treat this nexus of cultural-political-economic relationships in depth, but these remarks on South Korea's relationship with China and Indonesia are elaborated in the footnotes, ${ }^{5}$ and for an introduction to "the East Asian Miracle" see Page 1994; for a variety of perspectives on Asia-Pacific more broadly, see Ikenberry \& Mastanduno 2003.

${ }^{6}$ This is my translation of the user's name, which was written on Facebook in Korean characters. 